\title{
Integrating science and society in European Framework Programmes: Trends in project-level solicitations
}

\author{
Hannot Rodríguez $^{\text {a b } 1}$, Erik Fisher ${ }^{\text {a c }}$, and Daan Schuurbiers ${ }^{\mathrm{d}}$ \\ ${ }^{\mathrm{a}}$ Consortium for Science, Policy \& Outcomes, Arizona State University, PO Box 875603, Tempe AZ \\ 85287-5603, USA, e-mail: efisher1@asu.edu \\ ${ }^{b}$ Department of Philosophy, Faculty of Arts, University of the Basque Country UPV/EHU, Paseo de \\ la Universidad 5, 01006 Vitoria-Gasteiz, Spain, e-mail: hannot.rodriguez@ehu.es \\ ${ }^{\mathrm{c}}$ School of Politics and Global Studies, Arizona State University, PO Box 873902, Tempe AZ 85287- \\ 3902, USA \\ d De Proeffabriek, Lookwatering 36, 2614 KA Delft, The Netherlands, e-mail: daan@proeffabriek.nl
}

\begin{abstract}
As part of a larger trend across industrialized nations, European research policy discourse has placed increasing emphasis on socio-technical integration: the explicit incorporation of activities devoted to broader social aspects into scientific activities. In order to compare these high-level integration discourses against patterns at the level of resource allocation, we analyze nearly 2,500 research solicitations from the three European Framework Programmes for R\&D during the period 1998-2010. We identify four distinct types of integration (socioethical, stakeholder, socio-economic and industrial) that occur either as core or parallel components of R\&D solicitations. Quantitative analysis reveals an overall trend towards increasing integration, with requests integrating industrial and socio-economic aspects substantially outnumbering those integrating socio-ethical and stakeholder aspects - by a 2 to 1 margin. Meanwhile, calls for socio-technical integration have become slightly more extensive (ranging across a broader range of research areas addressed), significantly more pervasive (shifting from the periphery to the core of $\mathrm{R} \& \mathrm{D}$ practices), and arguably less diverse (involving a wider variety of integration types) over time. The relative lack of attention to socio-ethical aspects and stakeholder participation in European research is particularly notable given that we focus on potentially controversial areas (life sciences, energy, and nanotechnology), which likely overemphasizes the prevalence of integration throughout the Framework Programmes.
\end{abstract}

\footnotetext{
${ }^{1}$ Corresponding author. Tel.: +34 945 013986, fax: +34 945013200 .
} 
Keywords: socio-technical integration, EU Framework Programmes, research solicitations, ELSA (Ethical, Legal and Social Aspects), stakeholder engagement, responsible innovation

\section{Introduction}

As part of a larger trend across industrialized nations, European research policy discourse has placed increasing emphasis on socio-technical integration: the explicit incorporation of activities devoted to broadening the social and ethical aspects that are taken into account during core scientific and engineering research and development (R\&D) activities in such a way as to shape R\&D pathways in socially desirable ways. Policy mandates for sociotechnical integration have been documented in the United States (Bennett and Sarewitz, 2006; Fisher and Mahajan, 2006a), the United Kingdom (Macnaghten et al., 2005; Owen and Goldberg, 2010), Canada (Genome British Columbia, 2011; Ommer and the Coasts Under Stress Research Project Team, 2007), and throughout Europe (Stegmaier, 2009; Goorden et al., 2008).

This emphasis is also observed throughout the consecutive European Framework Programmes (FP) for Research and Technological Development, the European Union's main policy instrument for guiding European research. While some forms of integration can be traced back to earlier Framework Programmes, such as the consideration of Ethical, Legal and Social Aspects (ELSA) of research in the Second Framework Programme (FP2), the overall importance attached to the integration of ELSA and other modes of social considerations appears to have grown considerably since FP5.

In part an attempt to legitimize potentially controversial forms of publicly funded science and technology, the policy discourse on integration also reflects more explicitly normative and substantive goals, such as making R\&D processes more inclusive and accountable and opening up new research alternatives and meanings, and suggests that the success of the European research endeavor at least to some extent rests on the successful integration of science and society. The proposition of integrating science and society at the level of the research project, however, implies changes in both structure and agency regarding how science is justified, organized and conducted (e.g., Fisher et al., 2006; Gibbons et al., 1994; Smith et al., 2005). We expect that it faces considerable challenges, especially to the extent that it may signal alterations to established scientific cultural norms and institutional practices. We therefore ask to what extent the emphasis on socio-technical integration in 
high-level policy discourse plays out at the more practical level of formal solicitations for R\&D delivery.

In order to trace the various trends in integration in strategic policy discourse and gauge their effects at more practical levels of decision making and allocation, we have analyzed nearly 2,500 science and engineering research solicitations from indicative research areas in three EU Framework Programmes over a 12-year period: FP5 (1998-2002), FP6 (2002-2006) and FP7 (2007-2013 [our analysis ends in 2010]). Research solicitations are an understudied, yet widespread mechanism for the delivery of strategic R\&D goals by means of allocating resources for new science and engineering research projects, such as those called for inside the Framework Programmes. They allow us to look at policy discourse and practices at more fine-grained and routinized levels of science policy implementation in order to compare these to more prominent discourse and decision contexts. Hence, we focus on research solicitations within Framework Programmes as a bellwether for other forms of the integration of science and society. The analysis tracks the extent to which the research that is solicited in science and engineering areas is pervaded by the visions for socio-technical integration alluded to above, such as those coming from the FP7 "Science in Society" research area and other policy discourses.

In order to situate the integration of science and society broadly and within a general context, we expand the notion of socio-technical integration to include a range of related meanings identified in the FPs, including the consideration of aspects ranging from economic to ethical; the participation of stakeholder groups ranging from private industry to public citizenry; and interdisciplinary collaborations between social and natural scientists. ${ }^{2}$

\section{Socio-technical integration in EU research policy}

Consideration of social and ethical aspects of scientific and engineering research has long been on the agenda of European policy makers. High-level calls for integration can be found as early as FP2 (1987-1991), which mandated research on the ethical, legal and social aspects (ELSA) of scientific research. Similarly, calls for the integration of the socio-economic dimensions can be found in FP4 (1994-1998) through its "Targeted Socio-Economic

\footnotetext{
${ }^{2}$ Notably, we distinguish socio-technical integration from compliance, e.g., with regulatory standards and ethical principles, which also has an established policy history. Thus, we do not take into account the fact that R\&D activities in the EU Framework Programmes must be carried out "in compliance with fundamental ethical principles" (see The European Parliament and the Council of the European Union, 1999, p. 6; 2002a, p. 3; 2006, p. 5). In our view, principle-based compliance does not imply the same degree of institutional changes for the core of R\&D activities as does socio-technical integration.
} 
Research" programme. Yet from FP5 onwards, both the quantity and quality of calls for integration intensifies. The emphasis on socio-technical integration can be understood as largely motivated by a series of events that in the last two decades have progressively eroded the legitimacy of the European science and technology governance system, raising concerns over the social uptake of scientific-technological innovations. This erosion of legitimacy has been diagnosed, by the social studies of science first, and by policymakers later, as responding to the uneasiness of society with an innovation model in which public concerns about science and technology are not adequately considered.

The food crises that affected Europe in the 1990s (such as 'mad cow' disease, foot and mouth disease, and dioxin contamination in chickens) were seen as highlighting the deficiencies of risk analysis and regulatory procedures and created a general perception that policymakers were more aligned with the interests of industry than with the public interest, which "undermined public confidence in expert-based policy-making" (Commission of the European Communities, 2001, p. 19). The European backlash against agri-food biotechnology - fueled in part by the experience of these food crises — was interpreted as a social reaction against what an important sector of the European publics considered was the uncritical development of a potentially dangerous and unethical technology, whose health, environmental and ethical risks were arguably under-analyzed and under-regulated (EGE, 2009; Gaskell, 2008). ${ }^{3}$ These experiences have, it is largely concluded, forced policymakers to focus not only on the policy objectives that originally justified R\&D investments, but also on demonstrating to European publics that the social and ethical principles behind publicly funded R\&D practices are robust (McDonell, 1997). Over the last two decades pressure has also grown for scientific research to be evaluated not solely according to narrowly defined economic or technological criteria (Bozeman, 2007; Schuurbiers, 2010; von Schomberg, 2012), but according to a plurality of social and public values and interests (Heap, 2004; Wilsdon and Willis, 2004; Ziman, 1998). Descriptions of scientific research in terms of “Mode-2" (Nowotny et al., 2001), "post-normal” (Funtowicz and Ravetz, 1999), and “postacademic" (Ziman, 2000) science all relocate scientific legitimacy in a broader societal space.

\footnotetext{
${ }^{3}$ In the particular case of the governance of agri-food biotechnology, European policymakers tried to overcome social resistance to this technology with a set of regulatory reforms which included some integration measures, such as rules for mandatory information to the public prior to commercialization of GMOs, the introduction of ethical advice as an additional criterion for decision making, or the socio-economic assessment of approved GMOs (The European Parliament and the Council of the European Union, 2001).
} 
Socio-technical integration is thus framed by policy makers to a considerable extent as a legitimizing resource that is intended to facilitate the societal uptake of scientifictechnological innovations and, consequently, the EU's strategic goal, set in the Lisbon Strategy, of becoming "the leading knowledge-based economy in the world" (European Council, 2000, p. 12). This strategic vision of integration is evident in the development and inception of the European Research Area (ERA): in the working document Science, society and the citizen in Europe, the European Commission claimed, in the light of the "growing skepticism" and "hostility" of society toward the advances in knowledge and technology, that the relationships between science, technology and society "have to change because of the impact of science and research on competitiveness, growth and jobs and on the quality of life in Europe" (Commission of the European Communities, 2000a, p. 5). However, in addition to this instrumental framing, there are also indications that more normative goals also informed the ERA. According to Busquin, "democratic governance must ensure that social and economic issues are taken into consideration in research activities" (Busquin, 2003, p. 6). More recently, and in the more specific context of the Framework Programmes, the Commission stated that "For Europe to become the most advanced knowledge society in the world, it is imperative that legitimate societal concerns and needs concerning science and technology development are taken on board" (European Commission, 2007a, p. 4; see also European Commission, 2003a, p. 10).

Thus, alongside instrumental justifications for socio-technical integration, and even within the same statement, it is also framed substantively, as an early and potential source of critical reflection on R\&D activities, as well as normatively, as a form of more inclusive and accountable governance of research and innovation. In the rest of this section, we continue to elucidate the multiplicity of policy justifications that are used to frame socio-technical integration in the European context. We also identify three key characteristics of European socio-technical integration research policy, arguing that policy discourse at the agenda setting level has over the years called for integration to be more pervasive (moving closer to actual $\mathrm{R} \& \mathrm{D}$ practices), extensive (addressing a broader range of research areas) and diverse (involving a broader range of integration types).

\subsection{Pervasiveness}

One particular feature that emerges from key policy documents such as the European Action Plans and the official Communications from the European Commission is a stated interest in 
moving integration closer to project-level R\&D practices. While research activities in both the socio-economic and ELSA dimensions were carried out in earlier FPs, they were considered as 'stand-alone' activities, occurring in parallel to natural science and engineering research efforts (Elizalde, 1998). FP5, however, envisions a more far-reaching integration. Philippe Busquin, former European Commissioner for Research, introduced the concept of the European Research Area (ERA), where scientific research, technological development and innovation in Europe were meant explicitly to address the major challenges of the times. As a result, the socio-economic dimensions of research were to be integrated at the core of $\mathrm{R} \& \mathrm{D}$. According to Busquin: "the socio-economic dimension has been integrated into the specific programmes of the Fifth Framework Programme to take full account of the needs of European Society and of the economic and social challenges it faces" (Busquin, 2003, p. 6). More specifically, "The intention was to move away from research for its own sake and to turn the research towards current socio-economic problems" (Busquin, 2003, p. 6). This ambition was carried through to the Science and Society research area of FP6 and Science in Society of FP7. The Science in Society Work Programme in FP7 for instance envisages: " $a$ research process aiming as much at the harmonious societal integration of new scientific and technological knowledge as to achieving the specific objective of the research itself" (European Commission, 2007a, p. 6).

\subsection{Extensiveness}

In response to Busquin's vision of the European Research Area (ERA), program-level calls for integration of both the socio-economic and ELSA dimensions of research focused away from the periphery and onto the core of European R\&D. This rhetorical intensification was accompanied by a stated intention to extend integration across a wider range of research areas. While the consideration of ELSA issues was reserved exclusively for bio-medical research and the life sciences from FP2 to FP5 (Elizalde, 1998), calls for integration began to spread across new fields of research in later FPs. As the Science in Society Work Programme in FP7 stated: "The challenge today is to encourage [scientific and technological] actors in their own disciplines and fields to participate in developing Science in Society perspectives from the very beginning of the conception of their activities" (European Commission, 2007a, p. 6). Indeed, as of FP6, references to integration had started to emerge in policy documents and Work Programmes beyond those of Science and Society (FP6) and Science in Society (FP7). The Commission's Communication Towards a European Strategy for Nanotechnology 
specifically aims to: "integrate societal considerations into the $R \& D$ process at an early stage" (Commission of the European Communities, 2004, p. 3). Similarly, the Work Programme for "Food, Agriculture and Fisheries, and Biotechnology" of 2009 stipulates that: "Ethical, social, economic and wider cultural aspects are fully integrated within projects by encouraging the participation of experts in ethics, law, economics and the social sciences" (European Commission, 2008a, p. 4). To Bruno Hansen, the former Director of DG Life Sciences, this represented a "new approach for integrating the ethical, legal, social and wider cultural aspects into research projects" (Hansen, 2002, "Foreword"; emphasis in the original).

\subsection{Diversity}

In addition to the envisioned pervasiveness and extensiveness of calls for integration, a third characteristic of integration discourse is observed: the different types of integration called for in European policy increase over time. In FP2, calls for socio-technical integration are limited to the consideration of ELSA. In FP3, the integration of the socio-economic dimension appears. The first specific projects targeted specifically to small and medium-sized enterprises (SMEs) were piloted during FP3 (1990-1994). The interest in industrial integration increased in FP5: "Research priorities are determined using a problem-solving approach, tackling clearly defined social and industrial needs" (European Commission, 2000, p. 4).

In 2001 the European Commission launched a proposal for reforming the European governance system, in order to "open-up policy-making to make it more inclusive and accountable" (Commission of the European Communities, 2001, p. 8). As a result, the scope of socio-technical integration is now seen to include the involvement of a wider range of stakeholders and publics in R\&D activities. In FP6 and FP7, further diversification of integration is observed: in addition to calls for the integration of ELSA and the socioeconomic dimension, there are also calls for studies of public perceptions, science studies and gender studies, and in addition to the involvement of industry there are calls for the integration of dedicated stakeholders, patient groups and the "general public" through a range of communication and dialogue activities. In the Regulation (EC) No 2321/2002 concerning the rules for participation in FP6 it was stated that "Activities under the Sixth Framework Programme should (...) improve information for, and dialogue with, society" (The European Parliament and the Council of the European Union, 2002b, p. 24). This call for integrating 
society in R\&D activities was re-emphasized later in the transition from FP6 to FP7. Zoran Stančič, former Deputy Director-General of DG Research, claimed that: "More must be done (...) to find ways of actively engaging with civil society, stakeholder groups and the public at large in the preparation and execution of research" (Stančič, 2007, p. 1).

\section{Conceptual framework and method}

This section presents the conceptual framework for our empirical analysis. We justify the selection of research areas in our sample, present the unit of analysis and sample size.

\subsection{Selection of research areas}

The European Framework Programmes are the EU's main policy instrument to promote and support R\&D in Europe. The Framework Programmes have two main strategic objectives, as set out by the Maastricht Treaty of the European Union (TITLE XV: Research and technological development, Article 130f): "strengthening the scientific and technological bases of Community industry and encouraging it to become more competitive at international level” (European Union, 1992, p. 34). The first Framework Programme was launched in 1984, representing a small fraction of total public funding for research in Europe at that time. It covered the period from 1984-1987 and had a budget of approximately $€ 3$ billion. Since then, each consecutive Framework Programme has had a larger budget, extended EU activities in new fields of research, and progressively diversified available mechanisms, types of financial support and intervention methods. FP5 (1998-2002) had a total budget of $€ 15$ billion, and FP6 (2002-2006) € 18 billion, while FP7, the current Framework Programme (2007-2013) has a budget of over $€ 50$ billion, which represents a substantial increase compared to the previous Framework Programme FP6 (41\% at 2004 prices, 63\% at 2007 prices) (European Commission, 2007b, p. 6). ${ }^{4}$

Because of the sheer size and complexity of the FPs, a full discursive analysis of the content of all the research areas was not attempted. ${ }^{5}$ Rather, we select those research areas within the FPs for which the question of socio-technical integration is particularly relevant, being

\footnotetext{
${ }^{4}$ In this paper, one billion refers to one thousand million $(1,000,000,000)$.

${ }^{5}$ For example, the core Specific Programme of FP7, namely "Cooperation" (FP7 allocates over $€ 32$ billion to this programme alone), is sub-divided into ten distinct research areas that reflect the most important strategic fields of knowledge and technology for the EU: Health; Food, Agriculture and Fisheries, and Biotechnology; Information and Communication Technologies (ICTs); Nanosciences, Nanotechnologies, Materials and new Production Technologies; Energy; Environment (including Climate Change); Transport (including Aeronautics); Socio-economic Sciences and the Humanities; Security; and Space.
} 
strongly contested areas of research: the life sciences (food and health), energy research, and nanotechnology. In these research areas the policy commitments within the Science and Society Work Programme can be expected to take hold. ${ }^{6}$

Life sciences are focused on the study and modification of living organisms, including human beings, and for this reason have been traditionally contested on ethical grounds. Issues such as abortion and euthanasia, cloning and reproductive technologies, or stem cell research are a frequent matter of political and societal controversy. ${ }^{7}$ The genetic modification of plants is a contested topic also, mostly in the European context. The European "backlash" against agrifood biotechnology exemplifies fierce public debate about the limits of science and the manipulation of nature based on socio-ethical and environmental considerations (e.g., Levidow and Marris, 2001). Research on energy, on the other hand, confronts the problem of developing efficient and alternative energy sources in a context of human-induced climate change, depletion of resources, and nuclear accidents. The social debate on energy therefore goes beyond economic and technical considerations and necessarily embraces considerations of environmental, socio-ethical and political nature (e.g., Parks and Roberts, 2010; Voss et al., 2006). Finally, the capacity of nanoscale science and engineering to manipulate matter at molecular and atomic levels has been presented as a horizontal research area with the potential to pervade and revolutionize all sectors of industry. This revolutionary potential, based on a profoundly new understanding and manipulation of reality, has been said to raise significant cultural, ethical, political and economic issues (e.g., Mnyusiwalla et al., 2003; Renn and Roco, 2006).

The specific designations of these selected research areas in the FPs have changed over time, but still there is considerable continuity between them through the FPs-i.e., the thematic research areas continue along FP5, FP6 and FP7. For example, the continuation of the FP5

\footnotetext{
${ }^{6}$ Other research areas, such as ICTs and Security, are also sensitive in socio-ethical terms. The developments on ICTs and security systems trigger, for instance, a series of privacy and intimacy issues that require a profound ethical analysis. The EC notes, "progress in knowledge and technology, especially in fields such as life sciences and technologies and information technology, goes hand in hand with a growing number of ethical issues" (Commission of the European Communities, 2000b, p. 20). Thus, while we have selected prime areas sensitive to social and ethical concern, the scope of our study did not allow us to examine all such potential areas.

${ }^{7}$ A progressive intensification of integration discourse can be seen particularly in the case of life sciences research: in the FP6 research area "Life Sciences, Genomics and Biotechnology for Health," for instance, it is stated that "an active and early involvement in the above activities [i.e., research activities] of regulators, experts on ethics, patients and society at large will be necessary" (The Council of the European Union 2002, p. 10); in the FP7 research area "Food, Agriculture and Fisheries, and Biotechnology" it is claimed that "Ethical, social, economic and wider cultural aspects are fully integrated within projects by encouraging the participation of experts in ethics, law, economics and the social sciences" (European Commission, 2008a, p. 4).
} 
research area "Energy, Environment and Sustainable Development - Part B: Energy" in FP6 is "Sustainable Development, Global Change and Ecosystems - Sustainable Energy Systems," and the correlate in FP7 of these two previous research areas is the research area "Energy." The "Quality of Life and Management of Living Resources" research area includes both health and food issues in FP5, while FP6 and FP7 handle them through separate research areas, namely "Life Sciences, Genomics and Biotechnology for Health" and "Food Quality and Safety" in FP6, and "Health" and "Food, Agriculture and Fisheries, and Biotechnology" in FP7. Finally, both FP6 and FP7 include a new research area on nanosciences and nanotechnology that is absent in FP5 (see table 1$)^{8}$.

\footnotetext{
${ }^{8}$ We represent research solicitations in the following way: the Framework Programme, followed by the abbreviated name of the research area. For example, a research solicitation from the research area "Nanotechnology and Nanosciences, Knowledge-Based Multifunctional Materials, New Production Processes and Devices" in FP6 will be "FP6-NMP."
} 
Table 1

Research areas selected for the analysis of socio-technical integration in FP5, FP6 and FP7.

\begin{tabular}{|c|c|c|c|}
\hline & FP5 (1998-2002) & FP6 (2002-2006) & FP7 (2007-2013) [until 2010] \\
\hline Health & \multirow{2}{*}{$\begin{array}{l}\text { Quality of Life and } \\
\text { Management of Living } \\
\text { Resources (QoL) }\end{array}$} & $\begin{array}{l}\text { Life Sciences, Genomics and } \\
\text { Biotechnology for Health (LSH) }\end{array}$ & Health \\
\hline Food & & Food Quality and Safety (Food) & $\begin{array}{l}\text { Food, Agriculture and Fisheries, } \\
\text { and Biotechnology (Food) }\end{array}$ \\
\hline Energy & $\begin{array}{l}\text { Energy, Environment and } \\
\text { Sustainable Development - } \\
\text { Part B: Energy (Energy) }\end{array}$ & $\begin{array}{l}\text { Sustainable Development, Global Change } \\
\text { and Ecosystems - Sustainable Energy } \\
\text { Systems (Energy) }\end{array}$ & Energy \\
\hline Nano & & $\begin{array}{l}\text { Nanotechnology and Nanosciences, } \\
\text { Knowledge-Based Multifunctional } \\
\text { Materials, New Production Processes and } \\
\text { Devices (NMP) }\end{array}$ & $\begin{array}{l}\text { Nanosciences, Nanotechnologies, } \\
\text { Materials and New Production } \\
\text { Technologies (NMP) }\end{array}$ \\
\hline
\end{tabular}

\subsection{Unit of analysis}

The research solicitations that make up the FPs' work programmes represent the main unit of analysis. As stated above, research solicitations are a widespread yet understudied mechanism for the delivery of strategic R\&D goals by means of allocating resources for new research. The European Commission's FAQs about FP7 describes the work programme solicitations as follows:

“The individual 'work programmes' are the detailed implementation plans for the specific programmes, research themes ${ }^{9}$ and other activities under FP7. They specify the concrete scientific-technical, economic and societal objectives of each activity, providing both a broad background and the detailed technical content. They project a 'road map' of the planned calls for proposals. They also indicate for each call the instruments that will be available and the evaluation criteria that will be applied. Understanding the objectives of the work programme is essential for preparing a good proposal" (European Commission, 2011, “What are work programmes?”).

\footnotetext{
9 "Research themes" in FP7 refer to "research areas."
} 
Thus, research solicitations signify to potential proposers the goals and expectations of their authors and the criteria by which research proposals generated in response to the solicitations will be judged. Meanwhile, calls for broadening the aspects and participants involved in research have been seen, both traditionally (e.g., Polanyi, 1962) and more recently (e.g., Wynne, 2011), as potentially disruptive of research practices. While sponsored research activities cannot be assumed to mirror the content of the research solicitations to which they respond for funding, solicitations serve as an intermediary mechanism between policy and scientific communities and provide a credible basis for research evaluation. We therefore assume that if integration is found in R\&D solicitations it in turn signals some level of institutional change if not disruption, whether in terms of material practices (Fisher, 2007), expectations (Jasanoff, 1995; Smith et al., 2005), political symbolism (Pielke, 2012) or otherwise - and that these changes are rather unlikely. Focusing on research solicitations provides an indication of the extent to which broader policy discourses on integration are adopted at policy stages closer to the actual conduct of research. In particular, it enables us to ask whether and to what extent more central and commonplace research practices as evident in research solicitations may resemble wider discourse. Hence, we focus on the research solicitations within Framework Programmes as a bellwether for the broader European integration of science and society.

\subsection{Sample size and retention}

Our analysis consists of detailed visual inspection and coding of all the research solicitations within all of the work programmes included in the selected research areas. A total number of 2459 individual research solicitations were analyzed (669 in FP5, 836 in FP6, and 954 in FP7). ${ }^{10}$ For each individually designated solicitation, we determined whether or not it requests a form of socio-technical integration and, if so, what kind. To account for multiple types of integration within one sample, we defined one individual research solicitation such that it may contain several specific requests for integration. For example, the research solicitation "LSH-2002-1-2.5-1: Post genomic approaches for tackling asthma and autoimmune diseases" from FP6-LSH contains two requests, one for ethical reflection

\footnotetext{
${ }^{10}$ Successive updates of the work programmes may contain consecutive research solicitations with identical or very similar content and title. Such consecutive solicitations were counted according to the number of times the solicitation was open for submission of proposals. For example, the solicitation "4.1.1. Analysis and quantification of the impact of environmental factors on human health" in FP5-QoL was counted three times, according to the three calls for proposals open for this research solicitation in June 1999, March 2001 and January 2002, published in three consecutive work programmes (European Commission, 1999a; 2001a; 2001 b).
} 
(which we call "ELSA;" see section 3.1) and one for socio-economic research: "projects should include clearly identified components addressing the ethical issues and the socioeconomic and public health perspective” (European Commission, 2002a, p. 25). Unless otherwise stated, the results are based on the total number of requests for each integration kind (meaning that some solicitations have been counted more than once). Finally, for each solicitation, we identified one primary request; any additional requests were recorded as secondary requests. Importantly, in order to determine changes in the prevalence of integration over time (i.e., for successive FPs), the primary requests have been used to calculate the number of integrated solicitations as a percentage of the sample size. The research results thus provide both an indication of the total number of research solicitations that include reference to some form of integration, and the number of requests for particular kinds of integration (outnumbering the number of solicitations). ${ }^{11}$

In addition to determining the overall prevalence and composition of integrated solicitations within each FP, our analysis aims to gauge to what extent the characteristics of integration diversity, extensiveness and pervasiveness (observed at the programmatic level) have taken hold at the level of research solicitations and changed over time. Have solicitations for integration indeed become increasingly more diverse, extensive and pervasive? After explaining our classification of integrated solicitations and presenting quantitative findings in the following section, we examine these trends in more detail.

\section{Research findings: Empirical analysis of research solicitations in FP5, FP6 and FP7}

This section presents the findings of our analysis of the research solicitations in the sample. We first classify the data according to different types of integration found in the solicitations. We then analyze in more detail the prevalence and import of those candidates, and discuss to what extent they can be said to address the policy calls for socio-technical integration.

Finally, we trace growth in the diversity, extensiveness and pervasiveness of integration.

\footnotetext{
${ }^{11}$ Note that initiatives such as workshops, forums, conferences, think tanks, networking, or proposals for public debate and stakeholder dialogue that are unconnected with a specific research project and hence out of the immediate context of natural science and engineering research are not considered here as integrated research solicitations. Only those solicitations in which one or more forms of integration are called for as a core or parallel component of natural science and engineering research practices have been analyzed.
} 


\subsection{Classification: Types of integration solicited}

In order to place socio-technical integration within a generic context, we considered a wide range of research requests for integration within the solicitation texts of the work programmes. We identified four distinct 'types' of integration. The first and most predominant by far were requests for industrial integration: the integration of industrial actors in research and innovation activities. Industrial integration solicitations aim principally to involve private industry in research activities to facilitate the industrial-economic use and exploitation of research results. For instance, the solicitation "NMP-2009-4.0-3 Development of nanotechnology-based systems for molecular diagnostics and imaging” in FP7-NMP specifies that: "In order to ensure industrial relevance and impact of the research effort, the active participation of industrial partners represents an added value to the activities and this will be reflected in the evaluation" (European Commission, 2008b, pp. 30-1; emphasis added).

The second type involved forms of socio-economic integration: the explicit consideration of issues such as economic competitiveness, economic growth, and employment. For example, the solicitation "5.1.1. Sustainable agriculture: Plant health" from FP5-QoL establishes that "Projects must foresee transfer of the [research] results to economically active end-users and therefore examine relevant socio-economic aspects and all complementary multidisciplinary quantitative studies whose results will be needed at the point of use" (European Commission, 2001a, p. 21). Integration here signifies research on, and the anticipation of, the economic aspects of the scientific and engineering research to be conducted.

The third type of requests, which we have dubbed socio-ethical integration, was found to call specifically for the integration of actors or perspectives from the social sciences and humanities that are not explicitly socio-economic. Socio-ethical integration may occur either through the direct participation of social scientists and humanists in research activities or through the incorporation of insights from the social sciences and humanities by scientists and engineers themselves. Here were found requests for the integration of ELSA research, requests for studies into public perceptions and social acceptability, for dissemination activities and communication strategies, and for the integration of science studies and gender studies. The solicitation "NMP-FP6: 3.4.4.2: Tissue engineering, new biomimetic and biohybrid systems," for instance, included a request for ELSA research: "Ethical, legal and 
regulatory issues need to be addressed in parallel with RTD issues" (European Commission, 2002b, p. 11; emphasis added). Similarly, the solicitation "Sub-seabed carbon storage and the marine environment" in FP7-Energy called for a study of public perceptions: "Public perception of sub-seabed carbon storage should also be assessed" (European Commission, 2009, pp. 30-1; emphasis added).

The fourth and least prevalent type of calls involved the integration of knowledge and opinions of various non-academic and non-industrial actors by way of public and stakeholder engagement, which we termed stakeholder integration. For instance, the solicitation from FP6-LSH “LSH-2002-1.2.4-1: Development and production of cell lines for cell based therapies" stipulates that: "public dialogue will be a requirement" (European Commission, 2002a, pp. 23-4; emphasis added), and the solicitation "LSH-2003-1.2.4-2: Gene therapy of inherited diseases" specifies that "The project should (...) involve patients' associations" (European Commission, 2003b, p. 24).

\section{2. 'Loci' for integration: Core and parallel requests}

In addition to the distinction between various types of integration, we have also identified different loci for integration activities, identified here as parallel and core solicitations. A research request was classified as parallel when ethical, social, legal and wider cultural aspects are considered alongside but are not otherwise linked to any particular science and engineering R\&D activity. The solicitation "3.4.1.5. Ethical, legal, social aspects of research in nanotechnology" in FP6-NMP provides an example of a parallel request: "The issues to be addressed are ethical, legal (including, as the case may be, regulatory issues, establishing priorities for standards and metrology needs, and specific IPR aspects) and/or social (including, where relevant, foresight activities and the possible impact of nanotechnology, as such or in combination with information technology, nano-biology and/or cognitive sciences)" (European Commission, 2003c, p. 15). In contrast, a research request is classified as core when the consideration of ethical, social, legal and wider cultural aspects are integrated into the practice of science and engineering R\&D described in the solicitation. For instance, the solicitation "LSH-2005-1.2.4-1: Tissue engineering approaches to treating children with birth defects" from FP6-LSH is an example of core integration, with its request for integrating ELSA research into project activities: "Ethical, social and regulatory issues must be fully covered by the project”" (European Commission, 2005, p. 14). 


\subsection{Prevalence and composition of integration}

Having established the different types and loci of integration identified during our discursive analysis, this section presents the overall prevalence and composition of solicitations for integration. At first glance, total integration numbers suggest that integration classifies as an important category within the Framework Programmes: of all the solicitations in our sample, more than a third (888 out of 2459) include some reference to integration. Within those 888 solicitations we have identified 1262 individual requests (recall that one solicitation can include several requests). Of those 1262 requests, roughly two thirds (67\%) address industrial (487) and socio-economic (356) integration; the remaining 33\% is divided between socioethical (230) and stakeholder (189) integration (see Figure 1a).

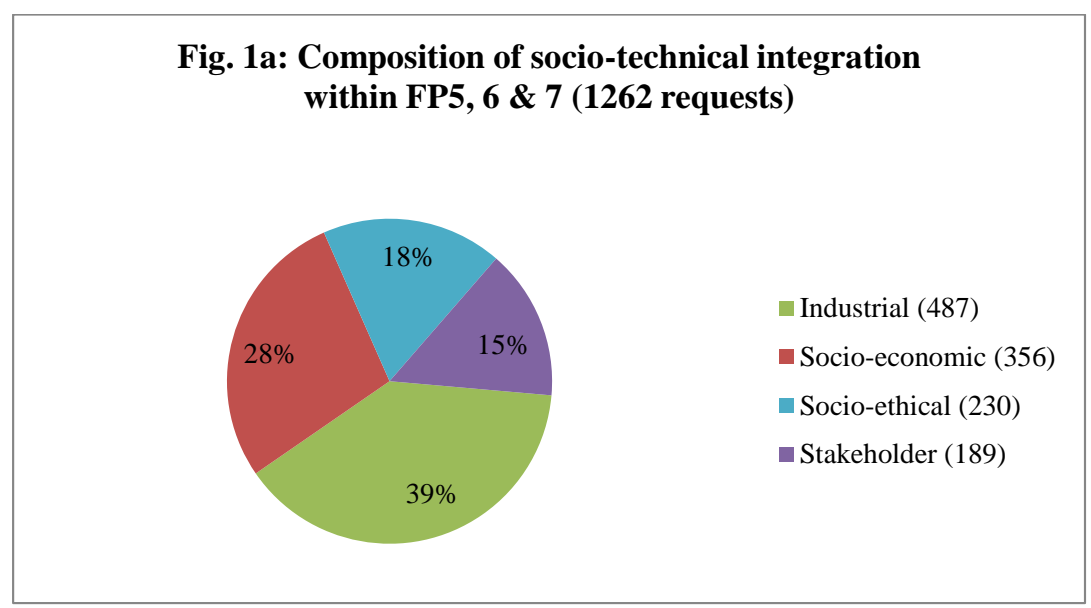

This suggests the Commission's predominant interest is in the industrial and socio-economic dimensions of integration. As the Maastricht Treaty of 1992 states: "strengthening the scientific and technological bases of Community industry and encouraging it to become more competitive at international level" (European Union, 1992, p. 34) has been a foundational objective for EU research policy (see above), and both socio-economic and industrial integration aim to direct $\mathrm{R} \& \mathrm{D}$ activities to address economic performance and improve the European economic outlook.

By contrast, the socio-ethical and stakeholder integration types more specifically address the explicit consideration of ethical, cultural and other broad social and public dimensions during R\&D. Together, these constitute one third of the total requests for integration. Within these categories, the large majority (175 out of 189) of the requests for 'stakeholder integration' 
call for the involvement of specific stakeholders in research, and a very significant portion of these (150 out of 175) focus on core integration. The remaining 14 out of 189 call for general public engagement (see Figure 1b).

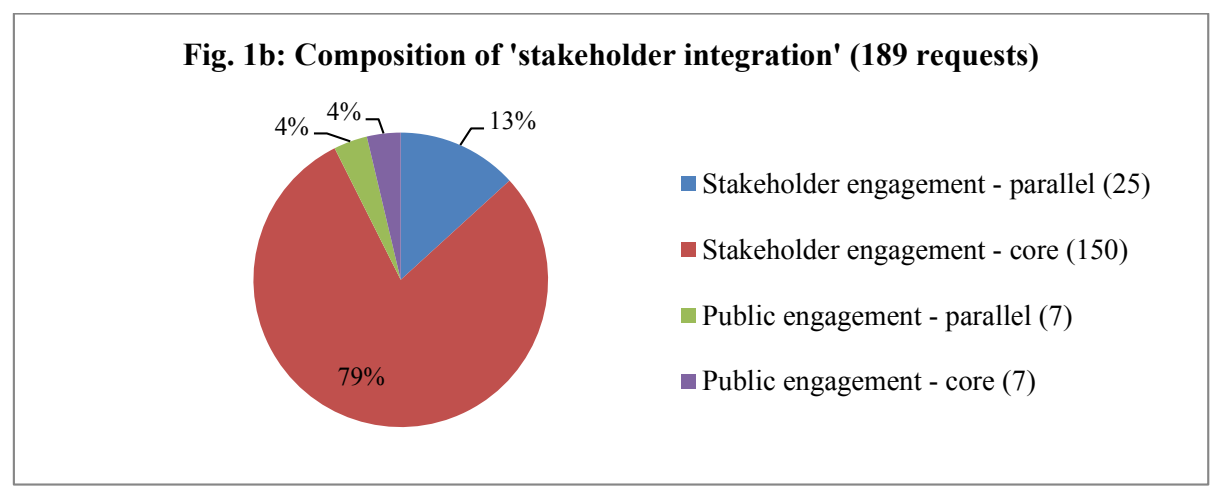

Within the category of 'socio-ethical' integration, requests for ELSA studies represent almost half of the total (100 out of 230). The second and third largest categories following ELSA are calls for dissemination activities (18\%) and communication strategies (10\%), together representing almost a third of the total. The remaining $29 \%$ of requests is a mixed bag, including integration of studies into public perceptions (10\%) and social acceptability (9\%), gender studies (6\%) and science studies (4\%) (see Figure 1c).

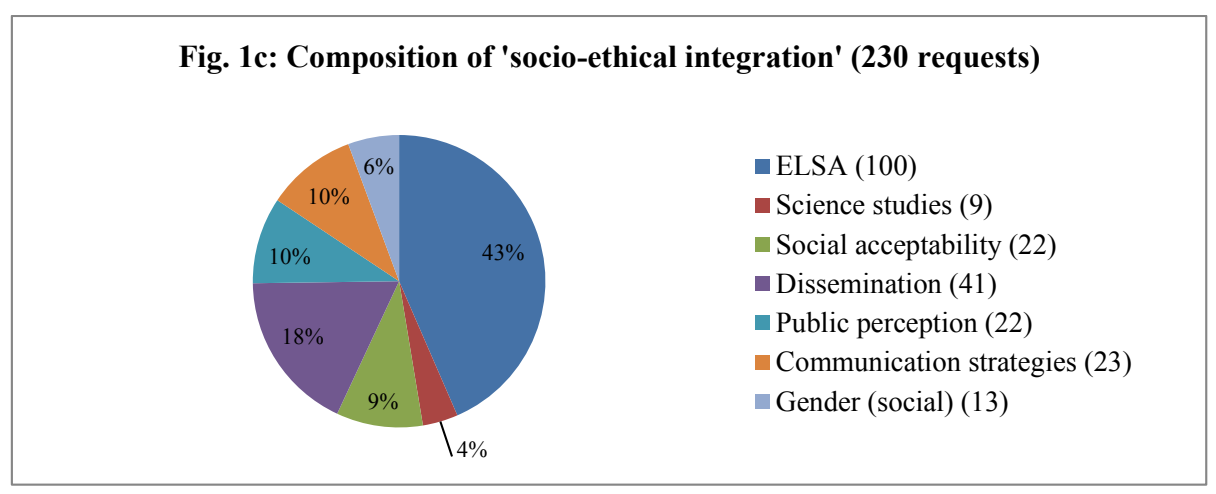

Up to this point we have considered the overall prevalence and composition of integrated solicitations within the three FPs. To examine the extent to which solicitations have responded to changes in policy discourse, we now look at changes that occur over time. The next section first considers the increase in the number of solicitations for integration over time; it then examines changes in integration diversity, extensiveness and pervasiveness. 


\subsubsection{Increase in solicitations for integration over time}

Calculating the number of solicitations calling for integration as a percentage of the sample size within each FP, the percentage of integrated solicitations on the whole increases, going up from $28 \%$ in FP5 to $46 \%$ in FP7 (see Figure 2). ${ }^{12}$ Defining socio-technical integration in the most general way, this result would appear to present a consistent trend towards increasing integration that would support the claims made in policy rhetoric.

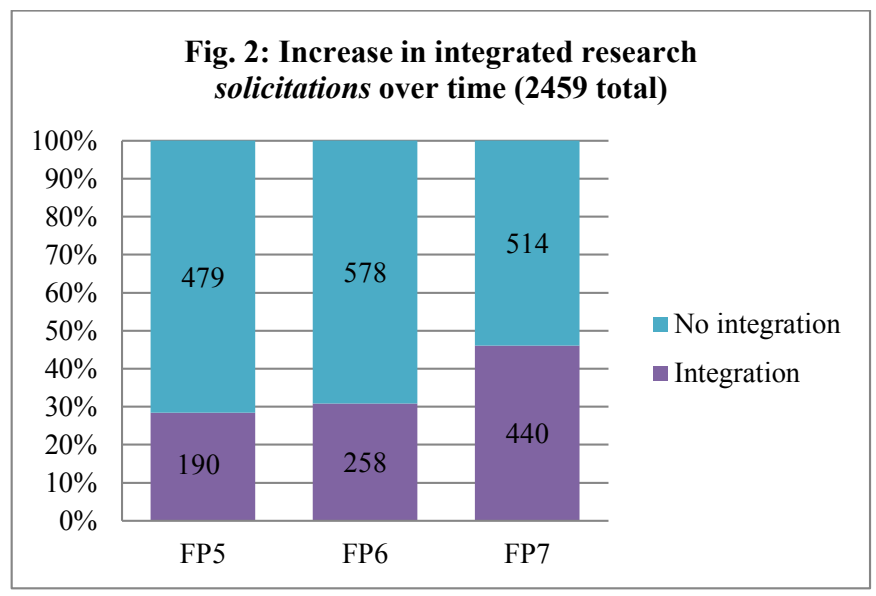

Note however that this overall trend is more varied if one looks at the level of individual types of integration. Requests for stakeholder integration for example represent $7 \%$ of the total solicitations in FP5, staying at 7\% in FP6 and going up to 9\% in FP7. Meanwhile, requests for socio-ethical integration move up from 9\% in FP5 to $11 \%$ in FP6, and down again to $9 \%$ in FP7. Thus, a somewhat more nuanced picture emerges: while overall integration numbers increase, specific forms of integration show more variation over time.

\subsection{2. 'Diversity' - variety of integration types}

Has integration become increasingly diverse, in accordance with policy discourses? In one sense, diversity increases from FP5 to FP6 with calls for industrial integration being articulated for the first time at the project level (but see footnote 12). However, diversity declines from FP6 to FP7 in the sense that the percentages of requests for industrial and

\footnotetext{
${ }^{12}$ The complete absence of any solicitations for industrial integration in FP5 is explained in part by the fact that the integration of industry is not called at the level of the specific research solicitation but open in principle for any research solicitation in that Framework Programme through the instruments "cooperative research" and "exploratory awards" (European Commission, 1999b). As already pointed out, our research only reports on forms of socio-technical integration that are specifically and explicitly called for in project-level solicitations.
} 
socio-economic integration both increase, while those for socio-ethical and stakeholder integration both decrease. Furthermore, socio-ethical and stakeholder integration types taken together show a general decline over the time period considered, from $40 \%$ of total requests in FP5 to $28 \%$ in $\mathrm{FP} 7,{ }^{13}$ while socio-economic and industrial integration types together increase from $60 \%$ in FP5 to $72 \%$ in FP7 (see Figure 3). ${ }^{14}$

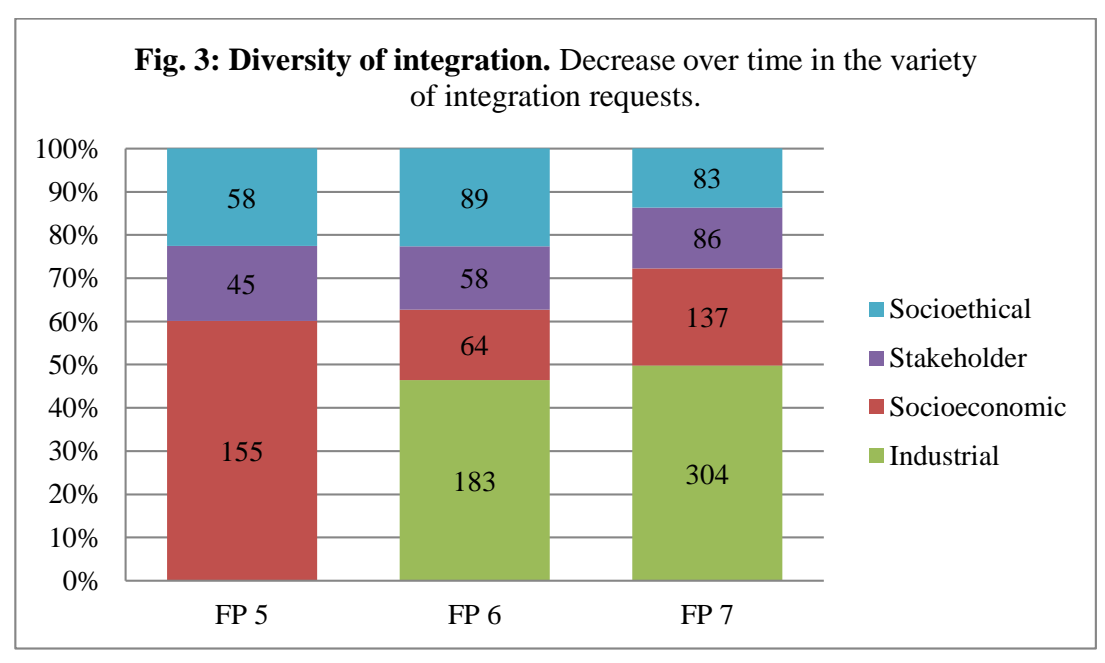

Measured with respect to one another, the different types of integration show less variety over time. Rather than a more diversified integration portfolio, we find an increasingly dominant focus on economic and industrial aspects and a corresponding decrease in socioethical and broader stakeholder issues, over time.

\subsection{3. 'Extensiveness'- the range of programmatic research areas addressed}

In terms of extensiveness, do the numbers indicate that integrated solicitations have permeated a wider range of research areas in response to policy discourse? Looking at the solicitations for each of the research areas identified within the FPs, we find that requests for socio-ethical and stakeholder integration almost exclusively occur in the specific FP5 programme QoL: 97 out of the 103 requests in total (94\%). The remaining 6 requests in the Energy-programme consist of 4 calls for social acceptability studies and 2 for dissemination.

\footnotetext{
${ }^{13}$ However, if we measure diversity in terms of the degree of variation within integration types. there are indications that integration has become somewhat more diverse over time within the categories of socio-ethical and stakeholder integration. Particularly within socio-ethical integration, there is a slight increase in the types of integration called for. Solicitations for dissemination studies increase significantly from 2 individual instances in FP5 to 25 in FP6, and there is an increase in requests for gender studies (2 in FP5, 3 in FP6, and 8 in FP7).

${ }^{14}$ Recall that in FP5 industrial integration is not called at the level of the specific research solicitation but is open in principle for any research solicitation (see footnote 12).
} 
Moving forward to FP6, 58 out of 147 requests for socio-ethical and stakeholder integration occur in the LSH-programme (39\%), compared with 44 in the Food-programme (30\%), 30 in the Energy-programme (20\%), and 15 for the new NMP-programme $(10 \%)$. This trend continues to some extent in FP7: 50 out of 169 in Health (30\%), 73 in Food (43\%), 35 in Energy (21\%) and 11 in Nanotechnology $(6 \%)$ (see Figure 4). ${ }^{15}$

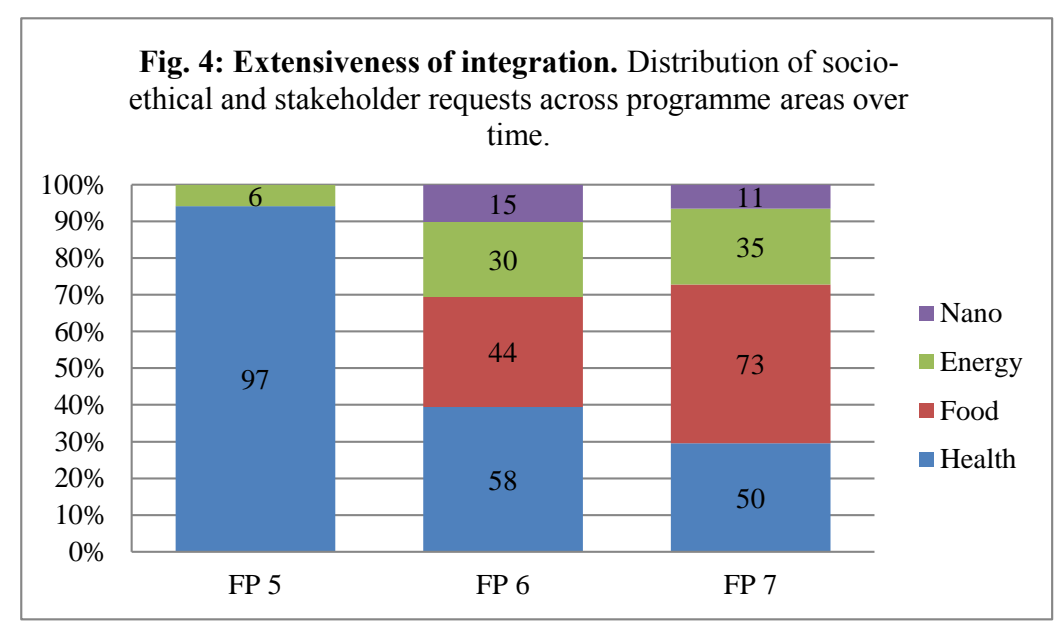

Generally speaking, the data in our sample confirm that solicitations for integration have become more extensive. But again, there is some variation: in the case of nanotechnology, requests for socio-ethical and stakeholder integration show a slight decrease moving from FP6 (15) to FP7 (11). Furthermore, the spread of integration to new areas correlates to a decrease of integration in Health.

\subsection{4. 'Pervasiveness' - from the periphery to the core of $R \& D$}

The third characteristic of policy discourse, pervasiveness, is most strongly reflected in the data. Looking specifically at the locus for integration, there is a clear shift from solicitations for parallel integration towards those for core integration as we move through the consecutive FPs. Across the board, solicitations for parallel integration diminish over time, coupled with a strong increase in solicitations for core integration. The ratio of parallel versus core integration shifts dramatically from FP5 to FP6 (from 125 parallel against 133 core requests

\footnotetext{
${ }^{15}$ Please note that in FP5 health and food issues are included in the research area "Quality of Life and Management of Living Resources" (QoL), while FP6 and FP7 handle them through separate research areas (see section 3.1). As a result, the FP5 "Health" column in Figure 4 includes both health and food issues.
}

Comment [v1]: The actual percentage, according to my calculation, is 6.5088 . wonder if we should write $7 \%$ instead $6 \%$. This is not a big deal though. I am not asking to change it. I am just providing the information.

NO, THIS MUST STAY AT 6\% OR THE NUMBERS WILL PRODUCE THE ABSURDITY OF 101\% 
in FP5, to 30 parallel against 364 core requests in FP6). This trend largely continues in FP7 (65 parallel against 545 core requests) (see Figure 5).

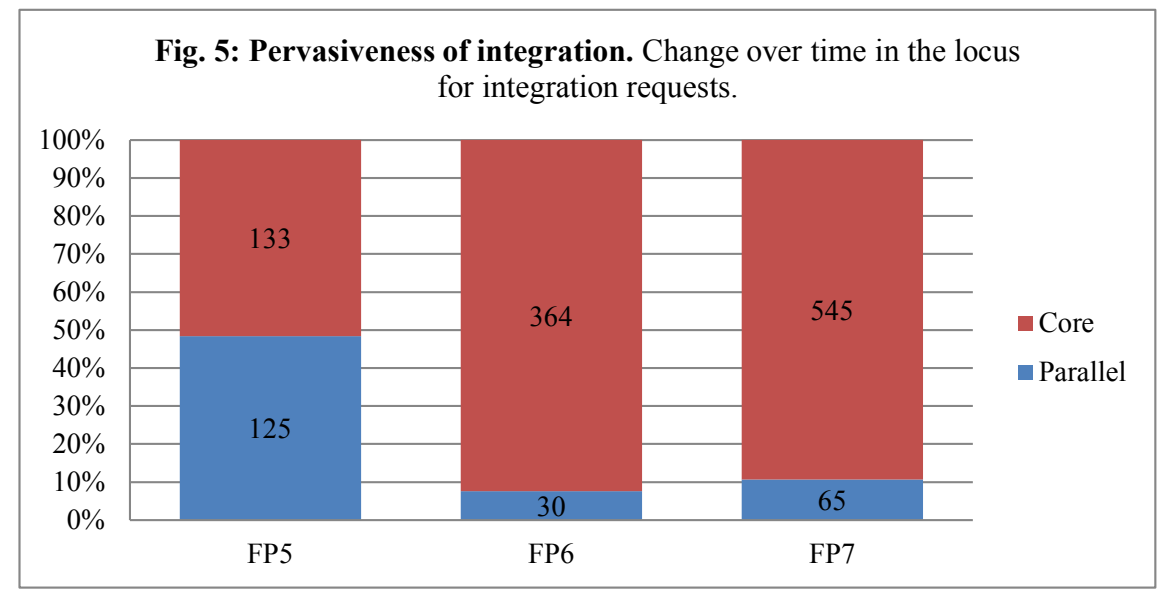

This shifting interest in the locus for integration is striking in the case of solicitations for ELSA-research. ELSA is exclusively a parallel activity in FP5: a total of 26 solicitations request ELSA-research in parallel to $R \& D$, and none request core integration of ELSAresearch. In FP6 however, this trend is reversed: there are only 6 solicitations for parallel ELSA-research, and 35 calls for core ELSA research. This complete reversal of interest in the locus for integrated ELSA research continues in FP7 (see Figure 6). 


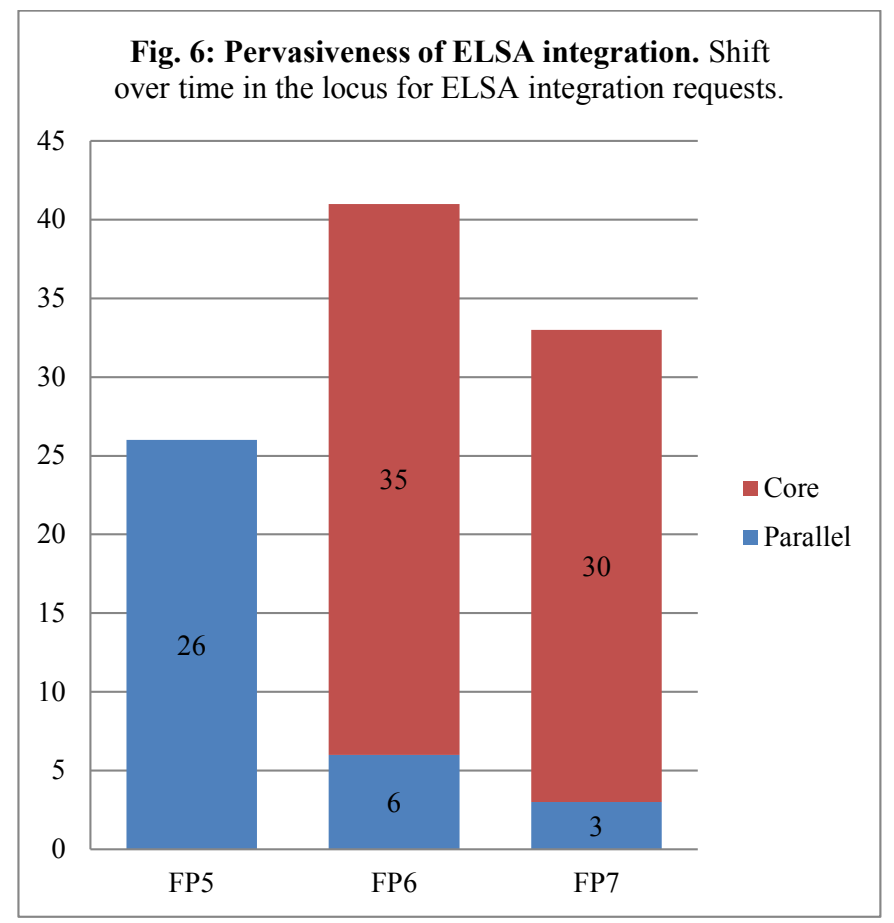

Relevant changes in the architecture of the different FPs may account for some of this effect: the reversal is less dramatic if we take into account that the decrease of parallel ELSA in both FP6 and FP7 coincides with the establishment of the Science and Society Work Programme in FP6 (and continued as Science in Society in FP7), targeted specifically at social sciences and humanities research, to aid the creation of the ERA. Hence, the decrease in calls for ELSA-research in the work programmes in our sample is offset by a probable increase in calls for parallel ELSA research within the Science and Society and the Science in Society research areas. In fact, we have identified some 20 ELSA research solicitations in FP6"Science and Society," and 20 research solicitations in FP7-"Science in Society." Taking these numbers into account makes the shift from parallel to core integration appear less significant. That said, the increase in calls for the consideration of ELSA integrated in core R\&D activities is noticeable. These figures suggest that the claims made in Science and Society and Science in Society areas with respect to the pervasiveness of integration have in fact taken hold in the work programmes in our sample. 


\section{Discussion}

Having presented the major research findings of our analysis, this section places these findings in the context of evolving broader European and international policy perspectives and discusses some critical questions in relation to them.

\subsection{Justifications evident in strategic policy discourse}

Policy justifications for socio-technical integration are manifold, and refer to a range of instrumental, normative and substantive goals - sometimes even in the same statement. Instrumental goals are those that serve as the means to other ends. Socio-technical integration is framed instrumentally when, for instance, it is seen as a legitimizing resource and as a route towards economic competitiveness. Integration is also framed normatively in relation to ends that are pursued for their own sake more than for the sake of others, such as securing the public interest and conducting policy in accordance with democratic values. Finally, integration is also framed substantively, in terms of goals and practices that are thought to lead to better ends, for instance the cultivation of diverse social perspectives among scientific research communities and during early stages of R\&D. ${ }^{16}$

Ultimately, socio-technical integration points to a fundamental tension: it is both an increasing governmental imperative in support of innovation for economic competitiveness and, under certain forms, interpretations and commitments, also a potential source of openness and conflict that may appear to hinder innovation for economic competitiveness. This tension, or ambiguity, related to integration, implies some flexibility in the way that it is framed and adopted, according to different interests and power dynamics (Stirling 2008). In this sense, we find especially that the integration of socio-ethical aspects at the practical level of $R \& D$ delivery reflects this tension, in terms of the scope and meaning of integration in the research solicitations.

\subsection{Assessing solicitations for $R \& D$ delivery in terms of strategic discourse}

Examining the research findings in light of the characteristics and justifications of high-level integration policy discourses, three main observations stand out with respect to our sample. The first is that socio-technical integration, as a generic category, has clearly increased over

\footnotetext{
${ }^{16}$ We draw largely on Stirling (2008) in formulating our understanding of instrumental, normative, and substantive justifications.
} 
time. This finding holds both for total number of requests for integration as well as for the relative number of integrated to non-integrated solicitations. This basic trend suggests that R\&D delivery at the project-level, as measured through the content of research solicitations, is increasingly in line with policy discourses that mandate the integration of science and society at the project level. The increase in the number of integrated solicitations from $28 \%$ in FP5 to $46 \%$ in FP7 suggests significant movement toward this general goal. This, together with the increasing extensiveness and pervasiveness of solicitations for integration across the programmes in our sample, provide evidence of the institutionalization of socio-technical integration, generically understood, within European research.

The second observation is that socio-economic and industrial forms of integration dominate the other forms. This suggests that instrumental policy goals for integration are making far more headway than are more substantive and normative goals. For, while strategic policy discourses justify integration in terms of multiple goals, when they justify it in terms of competitiveness and economic growth, they tend to stress socio-economic and industrial forms of integration. On the other hand, when they justify the integration of science and society normatively in terms of democratic values and substantively in terms of diversity of social perspectives, policy discourses tend to emphasize socio-ethical dimensions and public stakeholders over socio-economic and industrial ones. And yet, the percentage of solicitation requests ensuring that "Ethical, social, economic and wider cultural aspects are fully integrated within projects" (European Commission, 2008a, p. 4) and that focus on "actively engaging with civil society, stakeholder groups and the public at large in the preparation and execution of research" (Stančič, 2007, p. 1) do not increase, but actually decline. This, coupled with the finding that there are variations in the trends for stakeholder and socioethical integration requests, and that these same types of integration explain the decline in relative diversity among types of integration requests, suggests that the observed trends fall short of the more democratic and reflexive ambitions of high policy discourses. Particularly in relation to extensiveness, the substantive ambition of the FP7 Science in Society Work Programme to "encourage actors in their own disciplines and fields to participate in developing Science in Society perspectives" (European Commission, 2007a, p. 6) appears to have produced only minimal results. The report Challenging Futures of Science in Society Emerging trends and cutting-edge issues on the role of science in society along FP7 lends support to this conclusion. It states that: "A major weakness of SiS [Science in Society] is that it is not embedded in other parts of the Framework Programmes. This endangers the 
credibility of the SiS logic, and at the same time makes the science-in-society approach isolated compared with other EU-funded research projects" (MASIS Expert Group, 2009, p. 68). The low number of solicitations for ELSA integration, which constitutes the earliest type of integration mentioned in policy discourses and the most prevalent form of socio-ethical integration observed in the solicitations, is particularly noteworthy here. This second observation is all the more striking given that our sample is likely to be biased in favor of integration, not least being the emerging area of nanotechnology.

The third and final observation is that integration has become more pervasive over time, shifting from parallel to core forms of socio-technical integration. This shift suggests that integration has moved closer to the heart of the R\&D scientific enterprise, which is somewhat surprising given our assumption that 'core integration' would be disruptive of conventional science and engineering research activities and therefore somewhat unlikely. Rather, this finding appears to hold implications for the productive if not transformative potential of integration embedded in the core of $R \& D$ in light of policy goals. Increasing requests for socio-technical integration in core European research activities thus provides some evidence for the growing extent to which "transdisciplinary research activities, with a dynamic integration of theoretical and practical components from various disciplines" do in fact "constitute a substantial part of contemporary science systems" (Hessels and van Lente, 2008, p. 758).

\subsection{Integrated research in the United States}

Before reflecting on the implications of our findings for the future of European research, we offer some brief comparisons to socio-technical integration discourses in the United States. Socio-technical integration has been defined in high-level American policy discourse more closely with (to employ the terms used here) socio-ethical and public stakeholder dimensions, and in contrast to national competitiveness and economic justifications (Fisher and Mahajan, 2006a; Guston, 2008). Additionally, in the US integration has been predominantly associated with nanotechnology, both at strategic and at project levels (e.g., Barben et al., 2008; Gorman et al., 2009; Patra, 2011; Viseu and Maguire, 2012; Roco et al., 2011; NSTC, 2011), with emphasis also visible in the case of synthetic biology (Rabinow and Bennett, 2012). Moreover, it has been explicitly conceived in close connection to core science and engineering research activities, and in distinct contrast to prior forms of Ethical, Legal and

Social Implications (ELSI) research associated with genomic program (Bennett and Sarewitz, 
2006; Fisher, 2005; Winner, 2003). Finally, an emphasis on the productive and transformative quality of socio-technical integration is the distinct focus of a coordinated series of studies supported by the National Science Foundation and managed by the Center for Nanotechnology in Society at Arizona State University (e.g., Conley, 2011; Ellwood and Pandza, forthcoming; Fisher, 2007; Flipse et al., 2012; Schuurbiers, 2011). Thus, while similar tensions between public-ethical and national-industrial values can be observed, they appear to play out differently in the US, where the mechanism of socio-technical integration is distinguished from other ethics modes and governance considerations, and in the EU, where the said tension can be more readily located within the mechanism of socio-technical integration itself - at least judging from European policy discourse and the solicitations in our sample.

\subsection{Implications for integrated European research}

That we found the more instrumental aspects of socio-technical integration policy to predominate in our sample while the more normative and substantive aspects lack the same commitment to follow-through arguably reflects the more general situation in which science policy goals tend to follow dominant political economic assumptions. For, when framed institutionally as a facilitator of the social uptake of innovation and, therefore, as an important factor in the achievement of a fixed set of primary state economic goals, socio-technical integration appears to make headway. At the same time, socio-technical integration is a potential disruptor of the R\&D system under its more radical forms. Socio-ethical and democratic varieties of integration, when framed and promoted not for the sake of prevailing institutional commitments, but in substantive and normative terms as an early source of critical reflection on R\&D activities and as a form of more inclusive and accountable governance of research and innovation, may potentially alter established dynamics of practice and power underlying innovation commitments and appraisal criteria.

This account may help explain the failure to solicit more socio-ethical and general stakeholder forms of integration, but it does not appear to explain why solicitations for integration that takes place in proximity to core $R \& D$ practices has increased-a finding that appears counter-intuitive considering that socio-ethical integration, and particularly ELSAintegration, shows signs of becoming more pervasive. For integration would appear to be unlikely insofar as it has the aspiration if not the potential to "open up" (Stirling, 2008) scientific practices to more diverse social perspectives and productively disrupt science and 
innovation practices (Wynne, 2011). Indeed, there is increasing evidence for the productive if not transformative capacity of embedded insights and critiques from social scientific and humanistic perspectives to modulate core R\&D practices (e.g., Fisher, 2007; Flipse et al., 2012; Ribes and Bowker, 2009; Schuurbiers, 2011). ${ }^{17}$ In this case, we cautiously suggest that substantive forms of socio-technical integration are able, or are at least perceived by scientists and policy makers to be able, to contribute to more "robust" (Nowotny et al., 2001) forms of knowledge and technological development, especially if they offer "dual value," meaning that critical reflection can also support learning that in turn promotes creativity and innovation (Fisher and Mahajan, 2006b, p. 6).

The combination of increasing pervasiveness and decreasing diversity of socio-technical integration over time holds interesting and important implications for the future of European socio-technical integration, especially considering the recent evolution of the Science in Society research area towards Responsible Research and Innovation (cf. Owen et al., 2012), which will be a cross-cutting issue in Horizon 2020, the Commission's main funding instrument for 2014-2020. If socio-ethical and stakeholder forms of integration continues to be under-represented in comparison to industrial and economic forms, while the other trends continue, the emergence of a budding capacity on the part of integrative researchers from a variety of disciplines to simultaneously and explicitly pursue heterogeneous agendas-from state and regional competitiveness to critically reflective and democratic agendas - becomes doubtful. Moreover, in the absence of a central clearing house for social and ethical research projects, such as was arguably served by the Science in Society research area, the prospect of developing a dual socio-technical expertise that purports to articulate socio-ethical issues and public interests while at the same time operating in close proximity to core $R \& D$ goals and practices may come at a cost. For if European socio-technical integrative capacity does not remain responsive to broader scholarly responsibilities (Jasanoff, 2011) and stakeholder communities (Winner, 2003), there is less assurance that it will serve a significant role guiding or at least shaping R\&D activities. The paradoxical result could be a greater degree of socially transformative interdisciplinary $\mathrm{R} \& \mathrm{D}$, but one that develops with fewer opportunities for institutionally established self-critical reflection tempered by broader stakeholder perspectives.

\footnotetext{
${ }^{17}$ On the other hand, there is also evidence for the challenge and even impotence of such activities in light of entrenched scientific institutional practices and unfavorable power arragements (e.g., Doubleday and Viseu, 2010; Rabinow and Bennett, 2012; Rip, 2009; van Oudheusden, 2011).
} 


\subsection{Limitations of the approach}

While our analysis has potentially uncovered some insights about the role of integration at various levels of policy discourse, these observations make clear that it can only offer a first glance at the implications of integration discourse for European research structures and practices. Also we acknowledge some limitations in our approach. The first limitation is that, for purposes of maintaining a manageable dataset, our sample includes those research areas that are prone to calls for integration. This has given us an indication of the trends within those areas themselves, but we cannot infer whether similar or contrasting effects have occurred in other research areas. A follow-up analysis surveying other thematic programmes within the FPs may indicate to what extent these trends occur elsewhere. Second, budget allocations matter. Given that budgets are not equally divided among solicitations, some solicitations could be more significant than others. While we have chosen to consider research solicitations for reasons explained above, further research into budget allocations could prove worthwhile. Finally, we do not enquire into the responses to the solicitations in terms of the actual research grants. Scrutiny of the specific activities carried out in EU research projects that have responded to these solicitations for integration could shed further light on the ways in which increasing integration may alter established institutional structures and practices. These topics exceed the scope of the present paper, but are nevertheless acknowledged.

\section{Conclusions}

This paper has tracked the extent to which the EU research policy system integrates socioeconomic and socio-ethical issues as well as industrial and public perspectives into science and engineering $R \& D$ activities. Our analysis of nearly 2,500 research solicitations from the last three European Framework Programmes for R\&D shows that socio-technical integration, as broadly formulated in strategic policy discourses, increases over time at the level of the research solicitations that mediate and implement them. It thus lends support to claims for the increasing institutionalization of integration within European research policy. However, this finding is qualified by the observation that solicitation requests integrating industrial and socio-economic aspects dominate those integrating socio-ethical issues and stakeholders-by a 2 to 1 margin. Moreover, in contrast to the general increase in integrated solicitations, solicitations integrating socio-ethical issues and stakeholders into scientific research actually decrease over time. 
The results of this analysis point to a visible but qualified evolution in socio-technical integration along the three Framework Programmes. Generically understood, integrated solicitations increase progressively along the Framework Programmes in trends that correlate to some but not all high-level policy discourses and legislation about FP5, FP6 and FP7. In particular, there is a shift in the way in which socio-technical integration is conceived by policy makers during the transition FP5-FP7, and this at different levels: the integration of societal dimensions is claimed to occur (i) pervasively at the core of science and engineering $R \& D$ activities, integrating social scientists and humanists in research activities and incorporating insights from the social sciences and humanities by the natural scientists and engineers themselves; (ii) extensively in different research areas besides the life sciences, and (iii) diversely through the participation of diverse actors and perspectives (including both stakeholders and the public as a whole) in research activities.

Thus, while there is an overall increase in solicitations for integration, and while these solicitations become significantly more pervasive and slightly more extensive, they also become arguably less diverse over time. Research solicitations within the European FPs increasingly support industrial and socio-economic forms, but lag in supporting socio-ethical and stakeholder participatory forms of project-level socio-technical integration. Realizing the "harmonious societal integration of new scientific and technological knowledge" (European Commission, 2007a, p. 6) - at least at the level of European R\&D delivery as measured by the solicitations in our sample — will demand more substantial and diversified efforts.

\section{Acknowledgements}

Hannot Rodriguez's contribution is based on research supported by the Department of Education, Universities and Research of the Basque Government under a Postdoctoral Fellowship for the Improvement of Research Personnel in a Foreign Country (Ref. No.: BFI08.183; 2009-2010 2-year period). This research was primarily conducted at the Consortium for Science, Policy \& Outcomes (CSPO), and the Center for Nanotechnology in Society (CNS), both at Arizona State University. Erik Fisher's contribution is based on work supported by the National Science Foundation under Award \#0849101 and cooperative agreement \#0531194. The authors would like to thank David Guston for helpful feedback at 
various stages of this project and an anonymous reviewer for constructive criticism of earlier drafts. Any limitations and shortcomings of the work remain the responsibility of the authors.

\section{References}

Barben, D., Fisher, E., Selin, C., Guston, D.H., 2008. Anticipatory Governance of Nanotechnology: Foresight, Engagement, and Integration, in: Hackett, E.J., Amsterdamska, O., Lynch, M.E., Wajcman, J. (Eds), The Handbook of Science and Technology Studies (3rd ed). MIT Press, Cambridge, MA, pp. 979-1000.

Bennett, I., Sarewitz, D., 2006. Too Little, Too Late? Research Policies on the Societal Implications of Nanotechnology in the United States. Science as Culture 15, 309-25.

Bozeman, B., 2007. Public Values and Public Interest: Counterbalancing Economic Individualism. Georgetown University Press, Washington, D.C.

Busquin, P., 2003. Foreword, in: European Commission, Research DG, The overall socioeconomic dimension of community research in the fifth European framework programme. A synthesis report on the integration of the socio-economic related research activities of the European Community (1998-2002) (EUR 20577). Office for Official Publications of the European Communities, Luxembourg, p. 6.

Commission of the European Communities, 2000a. Science, society and the citizen in Europe. Brussels, 14.11.2000, SEC(2000) 1973.

Commission of the European Communities, 2000b. Towards a European Research Area. Brussels, 18.1.2000, $\operatorname{COM}(2000) 6$ final.

Commission of the European Communities, 2001. European Governance: A White Paper. Brussels, 25.7.2001, $\operatorname{COM}(2001) 428$ final.

Commission of the European Communities, 2004. Towards a European Strategy for Nanotechnology. Brussels, 12.5.2004, $\operatorname{COM(2004)~} 338$ final.

Conley, S.N., 2011. Engagement Agents in the Making: On the Front Lines of SocioTechnical Integration. Science and Engineering Ethics 17, 715-21.

Doubleday, R., Viseu, A., 2010. Questioning Interdisciplinarity: What Roles for LaboratoryBased Social Science?, in: Kjølberg, K.L., Wickson, F. (Eds), Nano Meets Macro: Social Perspectives on Nanoscale Sciences and Technologies. Pan Stanford Publishing, Singapore, pp. 55-84.

EGE - The European Group on Ethics in Science and New Technologies to the European Commission, 2009. Opinion No 24: Ethics of modern developments in agriculture technologies. European Commission (Brussels, 17 December 2008). Office for Official Publications of the European Communities, Luxembourg. 
Elizalde, J., 1998. General Introduction: ELSA in F.P. 4, in: European Commission, E(thical), L(egal) and S(ocial) A(spects) of the Life Sciences and Technologies

Programmes of Framework Programme IV. Catalogue of Contracts. EUR 18309, Brussels.

Ellwood, P., Pandza, K., forthcoming. Strategic and ethical foundations for responsible innovation. Research Policy.

European Commission, 1999a. Quality of Life and Management of Living Resources, Work Programme, March 1999 (A_WP_EN_199901.pdf). The Fifth Framework Programme.

Brussels.

European Commission, 1999b. Call for proposals for indirect RTD actions published by the specific programme for research, technological development and demonstration on promotion of innovation and encouragement of SME participation (1998 to 2002). Call identifier SME 1999/1 (1999/C 92/13). Official Journal of the European Communities (1.4.1999; C 92/14), Brussels.

European Commission, 2000. Innovation and SMEs: Breaking down the barriers to innovation and promoting research for small companies in Europe. Office for Official Publications of the European Communities, Luxembourg.

European Commission, 2001a. Quality of Life and Management of Living Resources, Work Programme 2001 (revised version Summer 2001) (QoL/PC- 523/2; 27.07.01). The Fifth Framework Programme, Brussels.

European Commission, 2001b. Quality of Life and Management of Living Resources, Work Programme 2002 (17.09.01). The Fifth Framework Programme, Brussels.

European Commission, 2002a. Work Programme for the specific programme for research, technological development and demonstration: "Integrating and strengthening the European Research Area," Priority 1: Life Sciences, Genomics and Biotechnology for Health. Edition December 2002 (09.12.2002, initial adoption). The Sixth Framework Programme, Brussels.

European Commission, 2002b. Thematic Area 3: Nanotechnology and nanosciences, knowledge-based multifunctional materials, new production processes and devices, Work Programme (09.12.2002, initial adoption). The Sixth Framework Programme, Brussels.

European Commission, 2003a. The overall socio-economic dimension of community research in the fifth European framework programme. A synthesis report on the integration of the socio-economic related research activities of the European Community (1998-2002) (EUR 20577). Office for Official Publications of the European Communities, Luxembourg.

European Commission, 2003b. Work Programme for the specific programme for research, technological development and demonstration: "Integrating and strengthening the European Research Area," Priority 1: Life Sciences, Genomics and Biotechnology for Health. Update July 2003. The Sixth Framework Programme, Brussels.

European Commission, 2003c. "Integrating and strengthening the European Research Area," Thematic Area 3: Nanotechnology and nanosciences knowledge-based multifunctional 
materials, new production processes and devices, Work Programme. Edition December 2003 (12.12.2003, $6^{\text {th }}$ update). The Sixth Framework Programme, Brussels.

European Commission, 2005. Work Programme for the specific programme for research, technological development and demonstration: "Integrating and strengthening the European Research Area," Priority 1: Life Sciences, Genomics and Biotechnology for Health. $16^{\text {th }}$ update, 7 July 2005. The Sixth Framework Programme, Brussels.

European Commission, 2007a. Work Programme 2007, Capacities, Part 5: Science in Society (C(2007)563 of 26.02.2007). The Seventh Framework Programme, Brussels.

European Commission, 2007b. FP7 in Brief. How to get involved in the EU 7th Framework Programme for Research. Office for Official Publications of the European Communities, Luxembourg.

European Commission, 2008a. Work Programme 2009, Cooperation, Theme 2, Food, Agriculture and Fisheries, and Biotechnology (C(2008)4598 of 28 August 2008). The Seventh Framework Programme, Brussels.

European Commission, 2008b. Work Programme 2009, Cooperation, Theme 4, Nanosciences, Nanotechnologies, Materials and New Production Technologies - NMP (C(2008)6827 of 17 November 2008). The Seventh Framework Programme, Brussels.

European Commission, 2009. Work Programme 2010, Cooperation, Theme 5, Energy (C(2009) 5893 of 29 July 2009). The Seventh Framework Programme, Brussels.

European Commission, 2011. What is FP7? Frequently Asked Questions (FAQs). http://cordis.europa.eu/fp7/faq_en.html (accessed on: 11/26/2011).

European Council, 2000. European Council, 23 and 24 March 2000, Lisbon: Conclusions of the Presidency. Bulletin of the European Parliament (27.03.2000), 01/S-2000, PE 289.667, pp. 9-29.

European Union, 1992. The Maastricht Treaty. Provisions Amending The Treaty Establishing The European Economic Community With A View To Establishing The European Community. Maastricht 7 February 1992. http://www.eurotreaties.com/maastrichtec.pdf (accessed on: 11/26/2011).

Fisher, E., 2005. Lessons learned from the Ethical, Legal and Social Implications program (ELSI): Planning societal implications research for the National Nanotechnology Program. Technology in Society 27, 321-8.

Fisher, E., 2007. Ethnographic Invention: Probing the Capacity of Laboratory Decisions. NanoEthics 1, 155-65.

Fisher, E., Mahajan, R.L., 2006a. Contradictory intent? US federal legislation on integrating societal concerns into nanotechnology research and development. Science and Public Policy 33, 5-16.

Fisher, E., Mahajan, R.L., 2006b. Midstream Modulation of Nanotechnology Research in an Academic Laboratory. Proceedings of "International Mechanical Engineering Congress 
and Exposition 2006." Paper no. IMECE2006-14790, pp. 189-95. Chicago, Illinois. November 5-10.

Fisher, E., Mahajan, R.L., Mitcham, C., 2006. Midstream Modulation of Technology: Governance from Within. Bulletin of Science, Technology and Society 26, 486-96.

Flipse, S.M., van der Sanden, M.C.A., Osseweijer, P., 2012. Midstream Modulation in Biotechnology Industry: Redefining What is 'Part of the Job' of Researchers in Industry. Science and Engineering Ethics. DOI 10.1007/s11948-012-9411-6 (Published online: 25 October 2012).

Funtowicz, S., Ravetz, J., 1999. Science for the Post-Normal Age. Futures 25, 739-55.

Gaskell, G., 2008. Lessons from the Bio-Decade: A Social Scientific Perspective, in: David, K., Thompson, P.B. (Eds), What Can Nanotechnology Learn from Biotechnology? Social and Ethical Lessons for Nanoscience from the Debate over Agrifood Biotechnology and GMOs. Academic Press, Amsterdam (et al.), pp. 237-59.

Genome British Columbia, 2011. Pathways to Integration. GSEAC Subcommittee on Pathways to Integration. March 23.

Gibbons, M., Limoges, C., Nowotny, H., Trow, M., Scott, P., Schwartzman, S., 1994. The New Production of Knowledge. Sage, London.

Goorden, L., van Oudheusden, M., Evers, J., Deblonde, M., 2008. Nanotechnologies for Tomorrow's Society: A Case for Reflective Action Research in Flanders, Belgium, in: Fisher, E., Selin, C., Wetmore, J.M. (Eds), The Yearbook of Nanotechnology in Society. Volume 1: Presenting Futures. Springer, New York, pp.163-82.

Gorman, M.E., Werhane, P.H., Swami, N., 2009. Moral Imagination, Trading Zones, and the Role of the Ethicist in Nanotechnology. NanoEthics 3, 185-95.

Guston, D.H., 2008. Innovation Policy: Not Just a Jumbo Shrimp. Nature 454, 940-1.

Hansen, B., 2002. Foreword, in: Sachez, E., Raguzzi, M., Vassarotti, A. (Coords); Caro (Ed), Ethical, Legal and Socio-Economic Aspects of Agriculture, Fisheries and Food Biotechnology. An overview of Research Activities 1994-2002. Office for Official Publications of the European Communities, Luxembourg.

Heap, B., 2004. Man and the Future Environment. European Review 12, 273-92.

Hessels, L.K., van Lente, H., 2008. Re-thinking new knowledge production: A literature review and a research agenda. Research Policy 37, 740-60.

Jasanoff, S., 1995. Product, process, or programme: three cultures and the regulation of biotechnology, in Bauer, M. (Ed), Resistance to new technology: nuclear power, information technology and biotechnology, Cambridge University Press, Cambridge, UK, pp. 311-31.

Jasanoff, S., 2011. Constitutional Moments in Governing Science and Technology. Science and Engineering Ethics 17, 621-38. 
Levidow, L., Marris, C., 2001. Science and governance in Europe: lessons from the case of agricultural biotechnology. Science and Public Policy 28, 345-60.

Macnaghten, P., Kearnes, M.B., Wynne, B., 2005. Nanotechnology, Governance, and Public Deliberation: What Role for the Social Sciences?, Science Communication 27, 268-91.

MASIS Expert Group, 2009. Challenging Futures of Science in Society: Emerging Trends and cutting-edge issues (EUR 24039). Publications Office of the European Union, Luxembourg.

McDonell, G., 1997. Scientific and Everyday Knowledge: Trust and the Politics of Environmental Initiatives. Social Studies of Science 27, 819-63.

Mnyusiwalla, A., Abdallah, S.D., Singer, P.A., 2003. 'Mind the gap': science and ethics in nanotechnology. Nanotechnology 14, R9-R13.

Nowotny, H., Scott, P., Gibbons, M., 2001. Re-Thinking Science: Knowledge and the Public in an Age of Uncertainty, Polity Press, Cambridge, UK.

NSTC, National Science and Technology Council, 2011. National Nanotechnology Initiative: Strategic Plan. Executive Office of the President of the US, Washington, DC.

Ommer, R.E. and the Coasts Under Stress Research Project Team, 2007. Coasts Under Stress: Restructuring and Social-Ecological Health. McGill-Queen's University Press, Montreal.

Owen, R., Goldberg, N., 2010. Responsible Innovation: A Pilot Study with the U.K. Engineering and Physical Sciences Research Council. Risk Analysis 30, 1699-707.

Owen, R., Macnaghten, P., Stilgoe, J., 2012. Responsible research and innovation: From science in society to science for society, with society. Science and Public Policy 39, 75160 .

Parks, B.C., Roberts, J.T., 2010. Climate Change, Social Theory and Justice. Theory, Culture \& Society 27(2-3), 134-66.

Patra, D., 2011. Responsible Development of Nanoscience and Nanotechnology: Contextualizing Socio-Technical Integration into the Nanofabrication Laboratories in the USA. NanoEthics 5, 143-57.

Pielke Jr., R., 2012. Basic Research as a Political Symbol. Minerva 50, 339-61.

Polanyi, M., 1962. The Republic of Science: Its Political and Economic Theory. Minerva 1, $54-73$.

Rabinow, P., Bennett, G., 2012. Designing Human Practices: An Experiment with Synthetic Biology. The University of Chicago Press, Chicago; London.

Renn, O., Roco, M.C., 2006. Nanotechnology and the need for risk governance. Journal of Nanoparticle Research 8, 153-91. 
Ribes, D., Bowker, G.C., 2009. Between meaning and machine: Learning to represent the knowledge of communities. Information and Organization. doi:10.1016/j.infoandorg.2009.04.001.

Rip, A., 2009. Futures of ELSA. EMBO Reports 10, 666-70.

Roco, M.H., Harthorn, B., Guston, D.H., Shapira, P., 2011. Innovative and responsible governance of nanotechnology for societal development. Journal of Nanoparticle Research $13,3557-90$.

Schuurbiers, D., 2010. Social Responsibility in Research Practice. Engaging Applied Scientists with the Socio-Ethical Context of their Work. Simon Stevin Series in Ethics of Technology, Delft.

Schuurbiers, D., 2011. What Happens in the Lab: Applying Midstream Modulation to Enhance Critical Reflection in the Laboratory. Science and Engineering Ethics 17, 769-88.

Smith, A., Stirling, A., Berkhout, F., 2005. The governance of sustainable socio-technical transitions. Research Policy 34, 1491-510.

Stančič, Z., 2007. Foreword, in: Braithwaite, M., Fries, R., Zadrozny, T., Wuiame, N., Anasagasti-Corta, M., Ings, N., Integrating Science in Society Issues in Scientific Research: Main Findings of the Study on the Integration of Science and Society Issues in the Sixth Framework Programme (Report to the European Commission). EUR 22976. Office for Official Publications of the European Communities, Luxembourg, p. 1.

Stegmaier, P., 2009. The rock 'n' roll of knowledge co-production. EMBO reports 10, 114-9.

Stirling, A., 2008. "Opening up" and "closing down": Power, participation and pluralism in the social appraisal of technology. Science, Technology, \& Human Values 33, 262-94.

The Council of the European Union, 2002. Council Decision of 30 September 2002 adopting a specific programme for research, technological development and demonstration: 'Integrating and strengthening the European Research Area' (2002-2006). Official Journal of the European Communities (29.10.2002; L 294/1). Brussels.

The European Parliament and the Council of the European Union, 1999. Decision No 182/1999/EC of the European Parliament and of the Council of 22 December 1998 concerning the fifth framework programme of the European Community for research, technological development and demonstration activities (1998 to 2002). Official Journal of the European Communities (1.2.1999; L 26/1), Brussels.

The European Parliament and the Council of the European Union, 2001. Directive 2001/18/EC of the European Parliament and of the Council of 12 March 2001 on the deliberate release into the environment of genetically modified organisms and repealing Council Directive 90/220/EEC. Official Journal of the European Communities (L 106/1, 17 April 2001), Brussels.

The European Parliament and the Council of the European Union, 2002a. Regulation (EC) No 2321/2002 of the European Parliament and of the Council of 16 December 2002 concerning the rules for the participation of undertakings, research centres and universities in, and for the dissemination of research results for, the implementation of the European 
Community Sixth Framework Programme (2002-2006). Official Journal of the European Communities (30.12.2002; L 355/23), Brussels.

The European Parliament and the Council of the European Union, 2002b. Decision No 1513/2002/EC of the European Parliament and of the Council of 27 June 2002 concerning the sixth framework programme of the European Community for research, technological development and demonstration activities, contributing to the creation of the European Research Area to innovation (2002 to 2006). Official Journal of the European Communities (29.8.2002; L 232/1), Brussels.

The European Parliament and the Council of the European Union, 2006. Decision No 1982/2006/EC of the European Parliament and of the Council of 18 December 2006 concerning the Seventh Framework Programme of the European Community for research, technological development and demonstration activities (2007-2013). Official Journal of the European Union (30.12.2006; L 412/1), Brussels.

van Oudheusden, M., 2011. Questioning 'Participation': A Critical Appraisal of its Conceptualization in a Flemish Participatory Technology Assessment. Science and Engineering Ethics 17, 673-90.

Viseu, A., Maguire, H., 2012. Integrating and Enacting 'Social and Ethical Issues' in Nanotechnology Practices. NanoEthics 6, 195-209.

von Schomberg, R., 2012. Prospects for Technology Assessment in a framework of responsible research and innovation, in: Dusseldorp, M., Beecroft, R. (Eds), Technikfolgen abschätzen lehren: Bildungspotenziale transdisziplinärer Methoden. Vs Verlag, Wiesbaden.

Voss, J-P., Bauknecht, D., Kemp, R., 2006. Reflexive Governance for Sustainable Development. Edward Elgar, Cheltenham, UK.

Wilsdon, J., Willis, R., 2004. See-through Science; Why Public Engagement Needs to Move Upstream. Demos, London.

Winner, L., 2003. Testimony of Langdon Winner before the United States Congress House Science Committee.

Wynne, B., 2011. Lab Work Goes Social, and Vice Versa: Strategising Public Engagement Processes. Science and Engineering Ethics 17, 791-800.

Ziman, J., 1998. Why must scientists become more ethically sensitive than they used to be? Science 282, 1813-4.

Ziman, J., 2000. Real Science: What it is, and what it means. Cambridge University Press, Cambridge, UK. 